III International Theoretical and Practical Conference "The Crossroads of the North and the East (Methodologies and Practices of Regional Development)"

DOI: $10.32743 /$ nesu.cross.2020.97-104

\title{
Extra-Curricular Mathematics and its Role in Development of General Cultural Competences in the Context of the Modern School
}

\section{Galina G. KRASHENNIKOVA}

Ph.D. (Pedagogics)

Associate Professor of the Department of Mathematics and Informatics

Institute of Digital Technology and Economics

North-Eastern State University

Magadan, Russia

E-mail: kroshga@yandex.ru

\author{
Maria A. MIRONOVA \\ 5th year bachelor's degree student \\ Institute of Digital Technology and Economics \\ North-Eastern State University \\ 4, Kommuny str., city of Magadan, Russia \\ E-mail: mashka0846@mail.ru
}

\begin{abstract}
The purpose of this research is to analyze modern forms of extra-curricular mathematical activities in a comprehensive school, to assess the influence of the form and the corresponding content of extra-curricular activities on formation of general cultural competencies of pupils. The general scientific methodology of this research is represented by the system approach, which is specific for most pedagogical researches. The theoretical analysis of pedagogical sources has been widely applied as one of the main methods of the pedagogical research. The research has revealed changes in the form and content of the extra-curricular activities that was caused by taking psychological characteristics of pupils into account; the research has also shown the relationship between forms of extra-curricular activities in the mathematics and general cultural pupils' competences, which are mostly formed by the influence of certain forms. This allows to distinguish the form classification approach, which is based on the goals of forming a certain type of general cultural competences.
\end{abstract}

Keywords: extra-curricular activities; mathematics; comprehensive school; general cultural competences; pedagogy.

\section{Introduction}

One of the urgent goals of modern school education is formation of general cultural competencies of pupils. A person, who is setting on his/her feet, must possess a combination of knowledge and skills that allow him/her to freely orient in the society around him, to find his place in this society. In the $21^{\text {st }}$ century, the society has reached such a state where personality traits such as creativity, capacity for self-development and self-realization come to the fore. The task of the school in formation of general cultural competencies is not only to enrich pupils with knowledge from various scientific disciplines, but also to develop their capacity for abstract thinking, analysis, synthesis, ability to act in non-standard situations and be responsible for made decisions. Each subject learned by pupils has its full range of tools that allows forming and developing the general cultural competencies of students. However, the most popular tools of pedagogical influence are those, which contribute to the growth of cognitive interest in the subject and cause the need to acquire knowledge through acting on the motivational sphere.

Mathematics traditionally refers to the subjects of the school course, which cause the greatest difficulties in studying. On the other hand, the role of mathematics in universal culture is enormous. 
The mathematical science has always served as a means of exploring the world; it reflects the history of human thought development. In addition, mathematics, with its accuracy and rigor, provides the most important resources necessary for the formation of a modern person. That is why both the Russian and the foreign methodology of teaching mathematics has always paid attention to the problem of formation of general cultural competencies of pupils (Dalinger, 2019; Kornhauser, 1993; Langefeld, 1987). A competency-based approach in education is a topic that many modern researches have devoted to (Schmidt-Hertha, 2020; Stegmann, 2020).

The purpose of the present research is to analyze modern forms of extra-curricular mathematical activities in a secondary school, and to assess the influence of the form and the corresponding content of extra-curricular activities on the formation of general cultural competencies of pupils.

\section{Methods}

In a broad sense, the pupils' general cultural competences acquired during the study of mathematics can be formulated based on the federal educational standards. According to the Federal State Educational Standard of Basic General Education the study of the "Mathematics" subject area should ensure:

- awareness of the importance of mathematics in everyday life;

- formation of ideas about the social, cultural and historical factors in establishing of the mathematical science;

- formation of ideas about mathematics as part of the universal human culture, as the universal language of science and the method of perception of reality, which allows to describe and study real processes and phenomena.

The main educational program of basic general education is implemented through both class and extra-curricular activities. Extra-curricular mathematics is an integral part of extra-curricular activities.

When organizing extra-curricular activities in mathematics, serious attention should be paid not only to its content, but also to the forms and methods of its implementation. On the one hand, the content dictates the form, and, on the other hand, the category type of pupils, the level of their mathematical training, and their psychological characteristics determine the choice of form. In terms of academic performance in mathematics, all pupils can be differentiated into three groups:

1) pupils that get behind in studying of the program material;

2) pupils with average performance in mathematics and with no interest in the subject;

3) pupils who demonstrate good abilities in studying mathematics and show heightened interest in the subject.

Different goal sets affect the ways of organizing work with each of the corresponding groups. Extra-curricular activities in mathematics with underachieving students is aimed at enhancing their mathematical skills up to a satisfactory level, and, if possible, to get them interested in mathematics as a general cultural phenomenon. In order to do this, it is necessary to involve such pupils in sporadically organized extra-curricular activities in mathematics in addition to the obligatory systematic "supportive" classes.

While organizing extra-curricular activities in mathematics with pupils of the second group, it is necessary to focus on formation of a sustainable motivation to study mathematics. In this case, initiating the educational activity of pupils requires their active inclusion in such forms of extracurricular activities that can be described as an "educational event." Recently, the concept of the "educational event" is increasingly encountered in pedagogical literature. The article presents the 
experience of teachers in organizing educational events (Sergeeva, 2016). In particular, it was noted that the educational event involves significant, creative action of people who are creating an innovative cultural situation here and now enriching the personal knowledge and personal experience of the participants in the events. It follows that the forms of extra-curricular activities in mathematics that can be attributed to such events should correspond to a certain cultural model: holiday, tournament, expedition, etc.

Finally, the work with pupils of the third group is a work with gifted children. In this situation the task of developing mental abilities, deepening and broadened knowledge in the field of mathematics is also in the first place. For this, systematic extra-curricular activities with the elements of scientific and practical research are organized. This type of activity includes, for example, such forms of extra-curricular work as a mathematical club, an elective course in mathematics, conferences of various levels, etc. However, at the same time, one should not avoid a certain entertainment of forms that is peculiar to educational events.

\section{Table 1. Traditional forms of extra-curricular activities}

\begin{tabular}{|c|c|}
\hline Groups & Forms \\
\hline $\begin{array}{l}\text { Pupils that get behind in } \\
\text { studying of the program } \\
\text { material }\end{array}$ & $\begin{array}{l}\text { - } \quad \text { additional classes of compensatory nature; } \\
\text { - } \quad \text { weeks, decades and months of mathematics; } \\
\text { - } \quad \text { thematic mathematical hours, lectures, discussions; } \\
\text { - } \quad \text { mathematical matinee and evenings; } \\
\text { - mathematical games, quizzes, competitions, KVN, mathematical } \\
\text { contests, tournaments; } \\
\text { - mathematical excursions; }\end{array}$ \\
\hline $\begin{array}{l}\text { Pupils with average } \\
\text { performance in mathematics } \\
\text { and with no interest in the } \\
\text { subject }\end{array}$ & $\begin{array}{l}\text { - } \quad \text { weeks, decades and months of mathematics; } \\
\text { - } \quad \text { thematic mathematical hours, lectures, discussions; } \\
\text { - mathematical matinee and evenings; } \\
\text { - mathematical games, quizzes, competitions, KVN, mathematical } \\
\text { contests, tournaments; } \\
\text { - mathematical wall newspapers, magazines, exhibitions; } \\
\text { - mathematical excursions; } \\
\text { - } \quad \text { mome reading, compositions on mathematical topics; } \\
\text { modeling. }\end{array}$ \\
\hline $\begin{array}{l}\text { Pupils who demonstrate good } \\
\text { abilities in studying } \\
\text { mathematics and show } \\
\text { heightened interest in the } \\
\text { subject }\end{array}$ & $\begin{array}{l}\text { - } \text { mathematics elective course; } \\
\text { - } \text { mathematical club; } \\
\text { - } \quad \text { weeks, decades and months of mathematics; } \\
\text { - } \quad \text { thematic mathematical hours, lectures, discussions; } \\
\text { - mathematical matinee and evenings; } \\
\text { - mathematical games, quizzes, competitions, KVN, mathematical } \\
\text { contests, tournaments; } \\
\text { - mathematical olympiads of various levels; } \\
\text { - mathematical wall newspapers, magazines, exhibitions; } \\
\text { - mathematical excursions; } \\
\text { - } \quad \text { home reading, compositions on mathematical topics; } \\
\text { - } \quad \text { modeling; }\end{array}$ \\
\hline
\end{tabular}

In the Table 1, it is shown that, despite all the differences between the pupils of the three selected groups, there are many traditional forms of extra-curricular activities in mathematics that can be successfully applied for pupils of all groups. These are mainly the forms that we identify with the educational event. That is why, using the theoretical-set mathematical apparatus for description of interaction and ratio of form variety of extra-curricular activities for each of the groups, we obtain the Euler-Venn diagram in the form shown in Figure 1. 


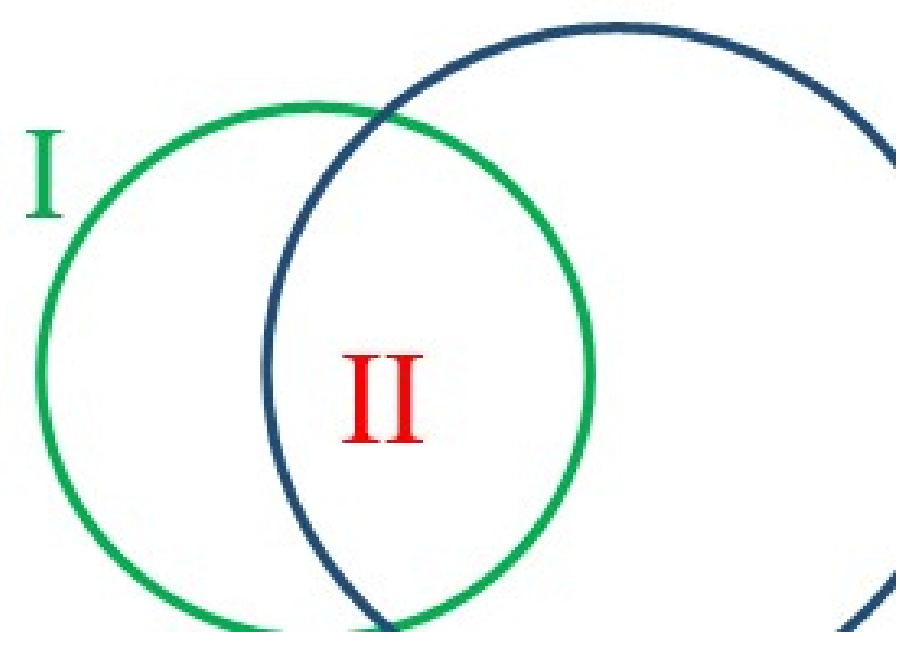

Figure 1. Ratio of form variety of extra-curricular activities for pupils of three groups

The forms of extra-curricular events applied for students of the second group can be successfully used both for organizing extra-curricular activities with pupils of the first group, and for working with pupils of the third group. Moreover, there are forms that are specific only for pupils of the first group, and forms that are specific only for pupils of the third group. However, there are no such forms of organizing extra-curricular activities with pupils of the second group that would be impossible to implement with pupils of either the first or the third groups. Thus, we can divide all forms of extra-curricular activities into three classes:
A. Forms that provide "supportive" events of compensatory nature.
B. Forms - "educational events."
C. Forms of organization of search activities, as well as of scientific and practical activities.

It can be shown that each group of forms solves its problems in terms of the formation of general cultural competences. For this purpose, we used the methods of the system analysis, which is widely used in pedagogical science. The system approach considers each set of objects of the surrounding world not as a simple set of objects, but as part of a whole that has a property that is not peculiar in each object individually. Moreover, by using the terms "pedagogical system", "education system", we operate exactly with the concepts of the systems and system analysis theory. The system analysis involves the decomposition of the system under study into individual components, and the subsequent synthesis of the obtained results as new knowledge. We conducted decomposition of the general cultural competences, which were formulated in a broad sense, into narrower components, and in the Table 2, we show what forms of extra-curricular activities provide formation of the corresponding components of these competences.

Considering the competences formed by pupils in extra-curricular mathematics classes, we should not forget to mention competences, which a teacher, who carries out this activity, should possess. First, we note here the facilitative component of the pedagogical competence. The concept of "facilitator" is widely used in the English-speaking world, but is little known to domestic teachers. Problems in development of facilitation competencies are associated with the insufficient readiness of this theme in relation to Russian education. At the same time, the facilitative teacher, who is using non-standard teaching methods, is not a new concept in foreign pedagogical literature. For example, in a work where forms of interactive learning are analyzed, it is emphasized that such activities require a facilitative teacher (Jones, 1988). Since our education has been guided by western standards in recent years, new forms and methods of organizing educational activities, 
including extra-curricular activities, come to our education along with competences, a certain transformation of the forms traditional for our school takes place.

The retrospective analysis of the forms of extra-curricular activities in mathematics demonstrated how the forms have been changing over time under the influence of various factors (Panisheva, 2017). In particular, the authors track this on the example of one of the forms - a mathematical holiday and related events. With variations of some components of this event, they also note the presence of certain invariants, peculiar to all these forms both in the past and in the present, among which are the goals of the activity. This allows to state that the classification of forms that we propose and which is based on the goals of forming a certain type of general cultural competences is also valid for newly emerging forms of extra-curricular activities in mathematics.

New forms of extra-curricular work in mathematics include, for example, activities developed on the basis of computer games; as well as events based on modern intellectual competitions, such as "Quiz, Please." Quest and strategy games are also very attractive for pupils. There are new types of olympiads and mathematics examinations conducted online in a test form. Mathematical wall newspapers and magazines have moved to a new format thanks to the development of modern information and computer technologies - they are being replaced by presentations and video clips. The previously used audiovisual teaching aids moved to a higher technological level, which gave an impulse to the emergence of new forms of extra-curricular activities in mathematics (Fuchs, 1976).

The emergence of new forms of extra-curricular activities in mathematics is due to many factors. The work by Knyazeva (2016) presents some sources of influence on the emergence of new forms of extra-curricular activities that are used in pedagogical theory and practice. In particular, these are:

1) new views and ideas of pupils;

2) new forms of cultural and educational events;

3) forms of presenting material provided in the media;

4) forms of citizen participation in public life;

5) new forms and technologies of work in various sectors of the economy;

6) new information technologies;

7) capability of virtual and real exchange of experience with colleagues; pedagogical innovations of teachers.

It is not unreasonable to assume that all of the above is reflected in the forms of extra-curricular activities, including activities in mathematics. Copying the external forms of adulthood is peculiar to children brought up according to the example and model of parents and other people around them. That is why the society, which is changing over time, and developing forms of interaction between people in the society cannot but affect the organization of education in this society. And regarding forms of interaction in the society - forms of citizen participation in public life, forms of citizen participation in economic life, forms and techniques of work in various sectors of the economy, forms of presenting materials on TV and the Internet - become forms of the so-called "informal" game component of the educational process, which can include some types of extracurricular activities in mathematics in a comprehensive school.

We would like to add to all of the above, that the thinking style of modern children has also changed. The modern young generation is growing in a very dynamic time and is surrounded by large amounts of information that falls upon them from all sides. And to a lesser extent they draw this information from books, most of information comes to them through audiovisual means, often 
chaotically and randomly. In this context a certain type of thinking is formed, which psychologists call clip thinking. Such people get used to the rapid change of events, they have a different way of processing information; visualization is very important for them. In addition, this requires new, more dynamic forms of organizing extra-curricular activities in turn.

Thus, in addition to the social and economic component, the emergence of new forms of extracurricular activities in mathematics is also influenced by the psychological component. This must always be taken into account when organizing extra-curricular activities in mathematics and choosing forms of extra-curricular events, since the basis of any pedagogical methodology is always the corresponding psychological theory that explains the behavior of participants in the pedagogical process and ensures the best implementation of the mechanism of interaction between pupils and teachers.

We also note that modern information and communication technologies not only lead to the emergence of new forms of extra-curricular activities in mathematics, but also allow us to transfer these activities to a new system level - remote organization of work. At present, the distant organization of extra-curricular activities in mathematics is not yet sufficiently advanced; the theoretical basis for organizing such work has not been developed; there have not been enough pedagogical experiments to draw conclusions about the positive and negative aspects of the distant organization of this type of pedagogical activity, the principles and common factors of such work have not been formulated. All this requires additional researches, both theoretical and practical. It is undeniable that they will follow, since in this direction we see the prospect of the development of the education system as a whole, and its individual components such as, in particular, extracurricular activities in mathematics for pupils of a comprehensive school. The perspectives of the remote organization of work is determined by the whole way of life in the modern Russian society; elements of such work are already present at all levels of education and there are more and more of them over time.

It is clear that distance extra-curricular activities in mathematics, as a new level of organization of extra-curricular work, should lead to the emergence of new forms of interaction with pupils. Consequently, in the future we are faced with the task of understanding what impact these new forms and remote work itself as a whole will have on formation of general cultural competences of pupils.

\section{Results}

Changes in the educational paradigm, due to passing of time, development of information technologies, as well as to turning points that affected our society at the end of the last century, have led to the change in all the components of the educational process. Goals, objectives, means, methods, forms and content of teaching mathematics have undergone changes to one degree or another. These changes have also touched extra-curricular activities in mathematics. Moreover, to a greater extent they touched upon the forms of organization of this type of educational activity.

However, while organizing any type of educational activity, the teacher should understand what competences of pupils should be formed or developed. In this regard, extra-curricular activities are no exception. We have examined the forms of organization of this activity, both traditional and modern, dividing all of their set into three main groups. The classification is based on the goals of forming a certain type of general cultural competences. General cultural competences formed within each group of forms are presented in the Table 2.

Table 2. The impact of extra-curricular activities on formation of cultural general cultural competences

Forms of extra-curricular activities General cultural competences


Forms that provide "supportive" events of compensatory nature

Forms - "educational events"

Forms of organization of search activities, as well as of scientific and practical activities

\section{Proficiency in solving problems}

Skills in applying mathematical knowledge in solving various problems and evaluating the obtained results.

Possession of logical reasoning

Capability for continuous brainwork

Possession of concepts of mathematical models

Capability for analysis and synthesis, induction and deduction

Abilities to accurately and competently express the thoughts using mathematical terminology and symbols, to carry out classifications, logical justifications, proofs of mathematical statements

Abilities to work in team, possession of social interaction skills, ability to choose the effective interaction structure

Possession of mathematical modeling methods

Ability to generalize mathematical material, flexibility of thought processes

Ability to choose rational solutions to problems

Possession of a wide range of mathematical tools and methods for perception of reality

In addition, dividing all students into three groups depending on their success and abilities in mathematics, we recommend for each group the most, in our opinion, optimal forms of extracurricular activities (Figure 2).

\begin{tabular}{l} 
1. Pupils that get behind in studying of \\
the program material \\
\hline $\begin{array}{l}\text { 2. Pupils with average performance in } \\
\text { mathematics and with no interest in } \\
\text { the subject }\end{array}$ \\
\hline $\begin{array}{l}\text { 3. Pupils who demonstrate good } \\
\text { abilities in studying mathematics and } \\
\text { show heightened interest in the }\end{array}$
\end{tabular}

Figure 2. Correspondence between pupils' groups and recommended extra-curricular forms

It should be noted that the considered groups of pupils become quite mobile with the correct organization of extra-curricular activities in mathematics, with the correct use of the forms and methods of this work by a teacher. In other words, individual pupils achieve a sufficiently high level of relevant general cultural competences over time, which will facilitate the transfer of these pupils from one group to another, and which will enable them to form and develop new mathematical and general cultural competences. Actually, this is one of the goals of extra-curricular activities in mathematics.

\section{Conclusion}


The analysis of the modern forms of extra-curricular mathematical activities allows us to assess their influence of on formation of general cultural competencies of pupils. Both historical sources of the past years and modern pedagogical literature, containing the latest results of pedagogical researches in this field, were used for the retrospective analysis. In addition, the authors took the experience of foreign pedagogy on this issue into account. Such methods as observation, survey, study of school documentation and pupils' performance were widely used as empirical methods for achieving desired goal. The researched revealed a change in the forms and content of extracurricular activities caused by considering various impact sources. It may be noted that the new forms fit well with our classification, and depending on belonging to a particular class, they can be recommended for use in organizing extra-curricular activities in mathematics with certain groups of pupils.

\section{References}

Dalinger, V.A. (2019). Methods of teaching mathematics - cognitive-visual approach. Moscow.

Fuchs, R. (1976). Audiovisuelle Lehrmittel: Methodik ihrer Anwendung und ihre Gestaltung [in German]. Leipzig: VEB Fotokinoverlag.

Jones, K. (1988). Interactive Learning Events: a Guide for Facilitators. London: Kogan Page; New York: Nickolas Publishing.

Knyazheva, V.V. (2016). Pedagogical techniques for selection and modeling of new forms of extracurricular activities. Problems and prospects of education development: materials of the 8th International Scientific Conference. Krasnodar, 227-231.

Kornhauser, A.W. (1993). How to study: suggestions for High School and College Students. Chicago; London: The University of Chicago Press.

Langefeld, U. (1987). Study Skills Strategies: how to Learn more in Less Time. London: Kogan Page.

Panisheva, O.V. (2017). Retrospective analysis of the forms of extra-curricular activities in mathematics in secondary school (from the second part of the 20th century to the beginning of the 21st century). Problems of modern pedagogical education, 54(2), 227-235.

Schmidt-Hertha, B. (2020). Vermittlung medienpädagogischer Kompetenz in der Fort- und Weiterbildung von Lehrkräften. Zeitschrift für Pädagogik [in German], 2, 191-207.

Sergeeva, E.E. (2016). Educational event as the resource for formation of universal learning activities among primary school pupils. Perm pedagogical journal, 8, 226-231.

Stegmann, K. (2020). Effekte digitalen Lernens auf den Wissens- und Kompetenzerwerb in der Schule. Zeitschrift für Pädagogik [in German], 2, 174-190. 